\title{
User-Centred Design for Collaborative 4D Modelling
}

\begin{abstract}
Four-dimensional (4D) modelling technology has potentials to integrate geographically dispersed planners to achieve collaborative construction planning. It originally allows individual planners to examine the robustness of a developed construction plan by linking its virtual three-dimensional (3D) model. However, applying this technology in teamwork remains challenges in computer-supported collaborative work $(\mathrm{CSCW})$. The purpose of this paper is to clarify the $\mathrm{CSCW} \underline{\text { in }}$ collaborative 4D modelling and its UI/interaction designs underpinned by usercentred design (UCD) for prototyping. Applying CSCW theories, the research firstly clarified the meaning of 4D CSCW to formulate design propositions as design target. Leveraging UCD theories, subsequently, the first stage research was carried out to seek an optimal standalone 4D modelling prototype following a parallel design approach. At the second stage, it further investigated into a collaborative 4D modelling prototype using an iterative design. It adopted collaborative task analysis into the UI/interaction design extension for a collaborative prototype based on results obtained from the first stage. The final usability testing was performed on the collaborative prototype to evaluate the designed CSCW and UI in a controlled geographically dispersed teamwork situation. The test results and user feedback verified their usability. It also disclosed design weaknesses in collaborators' awareness and smooth tasks' transitions for further enhancement. The combination of $\underline{\mathrm{CSCW}}$ and UCD theories are practical for designing collaborative $4 \mathrm{D}$ modelling. $\underline{\mathrm{It}}$ can also benefit designs for collaborative modelling in other dimensions like cost analysis, sustainable design, facility management, etc. in building information modelling (BIM).
\end{abstract}

Keywords: 4D modelling, BIM, CSCW, UCD, usability testing Paper type: Research Article 
Introduction

The construction industry is confronted with challenges from dynamic information project delivery, etc. (Wang et al., 2007; Baiden et al., 2006). A significant phenomenon in the construction field is that subcontractors of a project are often geographically dispersed. Related planners usually have different specialities and perform their own planning work in different locations. Their independent but interrelated planning can inevitably cause conflicts when their plans are integrated eventually. Considering these critical issues, it had been proposed to integrate construction project process so that to eliminate repeated work to improve effectiveness and efficiency in construction projects (Prescott, 1998).

Four-dimensional (4D) modelling (or 4D Computer-Aided Design (4D CAD), or 4D simulation) is one of computer simulation techniques that can simulate construction processes to disclose potential conflicts in construction plans (Collier et al., 1996). By linking specified construction tasks in a bar chart, the work breakdown structure (WBS), with associated components in a 3D building model, the product structure (PBS), the computer can generate a dynamic 3D construction sequence alone with time progressing in a standalone working situation. Through such an approach to 4D modelling, hidden conflicts in the construction plan can be possibly visualised and updated to improve the plan. Figure 1 shows a typical 4D modelling process that can enhance a developed construction plan through several linking-simulation-updating iterations.

$<<$ Insert Figure 1 here $>>$

4D modelling is highlighted to facilitate planners' teamwork for collaborative construction planning (Heesom et al., 2004). The bar chart based 4D modelling has demonstrated its usefulness in conflict-checking through online 4D simulation (Kang et al., 2007) and incorporating plan data from multiple planners in commercially 
available tools like Synchro 4D (Synchro, 2010), but not promoting planners' collaboration during the planning. As a matter of fact, the bar chart based 4D modelling is confined for collaboration because it requires a developed plan as input, which has no contribution from 3D models but relies on planner's imagination from 2D blue prints (Chau et al., 2005). This independent imaginary plan excludes planners' teamwork to make a plan.

Human computer studies suggest that a unique socio-technical context can foster collaborative work (Fischer et al., 2005). Being the only design illustration, a 3D building model provides a possibility to create a unique socio-technical context to achieve collaboration. Applying 3D building models for collaborative 4D modelling involves substantial socio-technical issues from network computing and humancomputer interaction (HCI). Its essence is to design suitable computer-supported collaborative work (CSCW) for 4D modelling to support both social and technical activities. Revealed from many expensive failures of developing software for CSCW, its successfulness primarily relies on its social aspects more than its technical aspects (Silva et al., 2000). Therefore, seeking suitable 4D CSCW designs based on 3D building model is critical to address collaborators' needs from both functional and $\underline{\text { non-functional perspectives to facilitate teamwork. }}$

The investigations of applying 3D building models for collaborative work are increasingly active in the architecture/engineering/construction (AEC) industry using information communication technology (ICT) (Shen et al., 2010), particularly with the advent of $\mathrm{BIM}_{2}$ which is an evolution from CAD to have all building information restored in a central repository for collaboration (Eastman et al., 2011). One of 3D BIM value propositions is as a collaborative environment, in which project team members can concentrate on the $3 \mathrm{D}$ model for communication and collaboration to understand project requirements and constraints in the construction phase (Grilo et al., 2010). To achieve this value, a theoretical study discussed technical requirements of a BIM server to be a collaboration platform (Singh et al., 2011).

From a software engineering perspective, two design patterns were proposed as reusable design templates at a low system level for facilitating synchronous communication and implementing these patterns in the design of collaborative 
environments (Isikdag et al., 2010). Additionally, commercially available tools like Tekla BIMSight, Autodesk Navisworks, Bentley Projectwise Navigator, GTeam, etc.

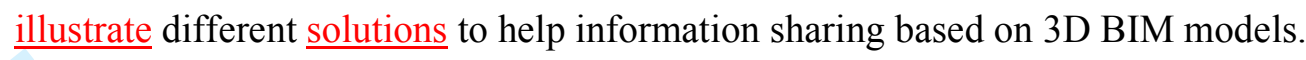
Given these studies and toolkits discussed and demonstrated from theoretical, technical and functional perspectives, research into model-based CSCW is still shortage in general and 4D CSCW in particular to promote teamwork in the AEC sector. It belongs to the priority ICT research area of human aspects management to enable people to work effectively and gain job satisfaction (Rezgui et al., 2006). It is also about usability engineering study for socio-technical systems in the HCI domain.

$\underline{\text { User-centred design (UCD) (or human-centred design) is an applicable approach to }}$ socio-technical system design (Baxter et al., 2011). It could benefit the design of 4D CSCW from user/system analysis, design and evaluation. The following contents discuss the application of CSCW and UCD theories for the 4D CSCW design. The discussion first shows theories of UCD and clarification of 4D CSCW to identify design target. Subsequently, it concentrates on the UCD applications for user/system analysis, design of 4D CSCW and related UI for prototyping and evaluation. Finally it highlights the evaluation findings, research method discussion and conclusions so as to improve research weaknesses for future studies of similar topics. Its knowledge contribution lies in the combination of CSCW with UCD theories to investigate collaborative 4D modelling in the AEC field.

\section{Theory of user-centred design}

$\underline{\text { ISO9241-11 defines usability as effectiveness, efficiency and satisfaction. It }}$ generalises essential non-functional needs of customers when they access ICT systems or digital products. UCD is a popular approach to achieving usability. It recommends placing the user at the center of the design. Since its initiation in the 1980s (Norman, 1988), UCD has been developing by HCI specialists into a set of techniques in analysis, design and evaluation for usability engineering. Its theory framework can be delineated from design approach, design workflow and evaluation $\underline{\text { method. }}$ 
$\underline{\text { Iterative design and parallel design are two approaches in UCD. The former needs }}$ several design-testing iterations to incrementally deliver usable designs. Although it gains popularity in the HCI field, its main shortcoming lies in limited design scope to explore proper design start points so as to obtain optimal designs (Dix, 2003). Compared with iterative design, parallel design permits some independent designs to be performed simultaneously and then integrate their suitable parts for further elaboration. This approach could accelerate the time-to-market of products and also create better designs but more expensive than iterative design (Nielson, 1996).

The iterative design workflow has been well documented. A roadmap of usability engineering lifecycle details relevant design activities step-by-step to guide designers to deliver usable designs (Mayhew, 1999). It deals with design work from several phases of user study, requirement analysis, conceptual design and usability testing. To $\underline{\text { initiate a design, it is important to access end users at the phase of user study to }}$ understand their features. Designers may perform questionnaire survey, interview, etc. to gain profiles of end users abstracted as personas for communication within a design team. Subsequently, platform constraint analysis, requirement analysis from both functional and behavioural aspects can contribute to the definition of usability goals. At the conceptual design phase, designers could create low fidelity, high fidelity or even working prototypes based on previous user and system analysis. The created prototypes need to be evaluated in usability testing.

A number of usability testing methods are available for designers to choose for evaluation according to their suitability (Nielson, 1993). These methods can be applicable for formative or summative evaluation. Formative evaluation is performed during design-testing iterations so that to find out design pitfalls for further improvement. Summative evaluation, on the other hand, is useful before finalising the product design to gain statistic results about to what extend the design is suitable. The number of participants in usability testing varies depending on selected methods. For example in formative evaluation, heuristic evaluation applies existing design guidelines or checklists without involving real users whilst thinking aloud evaluation requires 3-5 participants. Summative evaluation, however, asks for substantial participants in testing so that to have enough simple sizes for statistical reasons. The 
$\underline{\text { cost of selected testing method is also in direct proportion to the number of }}$ participants involved in testing (Hix, 1999).

Indicated from the UCD theory framework, designers have to decide proper techniques applying UCD to solve relevant problems. In terms of 4D CSCW design, it challenges the application of UCD theory in three aspects of clarifying its meanings, identifying users' needs for design and performing evaluation. The rest part of contents are organised as clarification of 4D CSCW meaning, UCD for 4D CSCW and usability testing to discuss these issues.

\section{Meaning of 4D CSCW}

Collaborative 4D modelling is a typical technology-push application because the current AEC industry is still dominated by two-dimensional (2D) drawings and paper documents rather than 3D-based semantic digital models. Thus, there are no marketpull issues like requirements from building designers or contractors, competitive products, observable working contexts, etc. to drive the invention of this technology application. The meaning of 4D CSCW for collaborative modelling is hence purely based on existing technology enablers, e.g. standalone 4D modelling, and CSCW theories. Defining collaborative 4D modelling and understanding its meaning can be helpful to elicit possible collaborators' needs so that to create proper CSCW $\underline{\text { designs }}$ and related functionalities for a group of planners to apply. This section highlights a collaborative 4D modelling enabler named interactive definition method and relevant design dimension leveraging $\mathrm{CSCW}$ theories to formulate possible design propositions. On the basis of these possibilities, it further identifies related functional requirements using use cases.

\section{Interactive definition method}

The interactive definition method is a collaborative 4D modelling approach that allows multiple planners to focus on a unique 3D building model for collaborative 4D | planning and simulation effectively across the Internet (Zhou et al., 2009). It is an 
extension of standalone 4D modelling dedicated to collaborative teamwork. Because the bar chart based 4D modelling approach is mainly applicable for standalone systems and individuals (Koo and Fischer, 2000), it needs an adaptation to satisfy collaborative 4D modelling in the network condition. Moreover, existing standalone 4D modelling applications are essentially 4D authoring tools to create 4D models. Therefore, the main usefulness of the interactive definition method is to create collaborative working contexts for 4D contents' development.

The interactive definition method requires a unique 3D building model (CAD or BIM format) as input to create an open shared socio-technical context. Within such a context, geographically dispersed planners can conduct three level interactions. At a high level, multidisciplinary planners can perform human-human communication to discuss planning strategies and formulate planning solutions. User-system interaction, at a middle level, enables planners to interactively conduct planning on the basis of inputted 3D building information. Through this interaction, a set of simulation items can be defined to describe both planning and simulation information. Created simulation items from planners are incorporated at a low level based on the network infrastructure. On the basis of these multilevel interactions with underlying supportive system functions, collaborative 4D modelling can lead to a synthesised robust plan along with its 4D simulation. In order to support planners' teamwork, designing proper $\mathrm{CSCW}$ at the high level and related UI at the middle level is essential for prototyping.

\section{Design dimension}

Design dimension can define a fundamental situation for people to work together following CSCW theories (Mills, 2003). There are ten key dimensions including Time, Space, Group size, Interaction style, Context, Infrastructure, Collaborator mobility, Privacy, Participant selection and Extensibility. Combining the interactive definition method with these dimensions, a distributed collaborative 4D modelling context is specified in Table 1 with highlighted keywords.

\footnotetext{
$<<$ Insert Table 1 here $>>$
} 
These specifications of the design dimensions describe the relationship among human, computer and their interactions, and a basic situation for planners to perform collaborative 4D modelling. In the human respect, the dimensions of space, group size, and collaborator mobility specify that the collaborators as a small plan team consist of a group of geographically dispersed planners. They perform planning work synchronously and collaboratively from different places. In the computer or system respect, the dimensions of infrastructure and extensibility imply that the collaborators apply a consistent system to perform collaborative work underpinned by system functions. The rest dimensions, moreover, indicate that this group of planners can perform social and user-system interactions concurrently and synchronously following certain collaborative protocols. Within the same planning context, planners can freely participate in related collaboration, and control their planning data according to their specialities. In order to achieve this collaboration, creating suitable collaborative work is critical for planners to promote their teamwork.

\section{Design proposition and use cases}

In the light of foregoing discussions about the interactive definition method and its $\mathrm{CSCW}$ design dimensions, the $4 \mathrm{D} \mathrm{CSCW}$ design is proposed to be a series of synchronous collaborative work. The work consists of co-talk, co-sort, co-plan, cosimulate and co-navigate. It has features in five design areas of communication, coordination, information access, interaction, and usability (Mills, 2003).

Collaborators can perform this work in either open or closed working session to achieve their collaboration. In an open session, team members as attendees can collaborate with each other while they still can receive information from other members who are not involved. In a closed session, attendees are in a focus group to concentrate on their collaboration without interruption from external sessions.

Co-talk is designed to support collaborators to perform human-human interaction during planning. Co-sort is created for collaborators' coordination and system access control before and during collaborative planning. It allows planners to concurrently retrieve 3D model, pick out their own building components and perform planning subsequently in their domains. Co-plan plays a dominant role in the group planning 
for information distribution, filtering, retrieval and structure. It permits collaborators to filter out their own working contexts from the retrieved 3D model so that to interactively define simulation items. Co-simulate across the network is positive for multiple planners to co-discover potential conflicts from a co-created plan. Conavigate enables collaborators to walk through, inspect and maintain the same focus in the distributed planning contexts. It is designed to produce What-I-See-Is-WhatYou-See (WISIWYS) feature in system. The proposed CSCW design with related features in the design areas as well as working session types is listed in Table 2.

$<<$ Insert Table 2 here $>>$

In accordance with the interactive definition method and the proposed $4 \mathrm{D} \underline{\mathrm{CSCW}}$ design, construction planners need to interactively and collaboratively define simulation items so that to create a construction plan and generate associated 4D simulation. Its software ought to enable a group of planners to carry out individual work in their client sides and collaborative work via a server connection. Related functional requirements of the software can be modelled using the Unified Modelling Language (UML) use case diagram (Schmuller, 2004). It contributes to the identification of specific collaborative situations from a user point of view. A highlevel use case diagram was created for describing both client side application and server side application (Figure 2).

$<<$ Insert Figure 2 here $>>$

\section{$\underline{\mathrm{UCD} \text { for } 4 \mathrm{D} \text { CSCW }}$}

The clarification of 4D CSCW meaning and use cases lays the foundation to start the design work applying UCD at two stages. At the first stage, the design adopts a parallel approach to delivering a usable and optimal design for prototyping standalone 4D modelling. At the second stage, design practices target collaborative issues for further exploration following an iterative approach. The purpose of performing a parallel design at the first stage is to quicker obtain optimal designs so that to explore collaborative work solutions at the second stage. This parallel design follows the 
$\underline{\text { UCD workflow to address user study, task analysis, parallel design prototyping, }}$ usability evaluation and design optimisation. Detailed information of this parallel $\underline{\mathrm{UCD}}$ is beyond the scope of this paper. In order to report coherent UCD process, this section briefly presents the user study results and related UI designs gained at the first stage. It further discusses details about the iterative design, consisting of user/system analysis, UI/interaction design and usability testing, performed at the second stage for 4D CSCW prototyping.

\section{$\underline{\text { User study }}$}

The purpose of user study is to understand potential end users and highlight their features in profile using persona for UI and interaction design. The benefits of persona creation lie in representing important features of diverse end users. It is thus convenient to understand and communicate users' information throughout design process (Pruitt, 2006). A questionnaire survey was conducted for a group of part-time postgraduate students studying construction management at the University of Wolverhampton. It acquired their information from four aspects: company situation about 3D CAD and planning software deployment, attitude and motivation about learning these software packages, knowledge and experience in using these software packages, and their physical characteristics. On the basis of this survey, a generated persona is stated as follows:

John Smith is a 38-year-old senior consultant in a construction consultancy. He obtained a Bachelor's degree in civil engineering from his university 15 years ago. His daily work is to create $3 D$ building model by translating clients' $2 D$ drafts for $3 D$ visualisation. Besides this duty, he also provides services of generating detailed construction plans for his clients. 3D Studio MAX and AutoCAD are his major working tools in 3D modelling while Microsoft Project is his favourite utility to make project plans. Because of geographically dispersed clients, he needs to contact them via the Internet. Being a good user in both 3D CAD and Internet applications, John is also skilful for software programming for better automating $3 D$ modelling in his work. However, fast-paced work and life only enable him to gain new skills from ease-of-use application. In order to catch up with the latest ICT advancement in the construction industry, he is now a part-time student at a university for studying the master's 
The online planner's task model (Figure 3) illustrates the planner's tasks conducted in the network condition. It includes the online individual tasks of navigate 3D model, sort PBS elements from the 3D model, define simulation items, and simulate a plan. Corresponding to the use case diagram, these tasks also can be performed collaboratively in a closed session. For the purpose of conducting this kind of collaboration, the planner needs to perform an extra task of select collaborators. Once a collaborator is selected, those individual tasks then become co-navigate, co-sort, coplan and co-simulate for collaboration. Thereafter, the online planner can conduct the collaborative task of select collaboration from them to prepare launching a collaborative session. As a fundamental task, navigate 3D model was designed to has a priority relationship of concurrent with information exchange to other tasks in the task model. It means that the planner can simultaneously perform navigation operations within these tasks' performances. 


\section{$<<$ Insert Figure 3 here $>>$}

The collaborator's task model (Figure 4) is similar to that of online planner's. The difference lies in no task of select collaborators but the collaborative task of accept an invitation. The collaborator must conduct this task to response to a session holder so that to initiate a closed collaborative session. During this session, the collaborator as a session attendee is subject to the session holder in navigation, 3D element displaying, and simulation progress control. These collaborative tasks performed by both session holder and session attendee build a general collaborative task, namely launch a collaborative session (Figure 5). Its task model illustrates the conditional session creation procedure that session holder sends an invitation to an intended collaborator, who then accepts the invitation to start the collaborative session.

$<<$ Insert Figure 4 here $>>$

$<<$ Insert Figure 5 here $>>$

Considering the features of end users represented by persona, usability goals are identified and defined as effectiveness and satisfaction when performing these proposed CSCW tasks. The usability evaluation targets them for testing.

\section{UI design}

Based on the optimal standalone 4D modelling prototype gained at the first stage, the client side $\mathrm{UI} /$ interaction design for $\mathrm{CSCW}$ at the second stage still targets the persona who has knowledge and working experience of construction planning and 3D CAD toolkits. Therefore, the further UI/interaction designs for the 4D CSCW system and collaborators inherit the standalone prototype feature of direct manipulations using standard input devices like mouse and keyboard via graphical user interface (GUI) without menu assistance. The same layout of UI design keeps a consistent working environment for both single planners and collaborators. For specific task operations, it applies different panel controls to support users' performances individually and 
collaboratively. This section highlights the differences between the standalone and collaborative prototypes in their UI/interaction designs.

\section{- Layout}

The general UI layout consists of three areas of system management, task selection and work visualisation to satisfy the user's tasks (Figure 6). The system management area provides the user with a unique entry on the top of the screen to control the system for planning work preparation. It has four buttons of network, load, scenario and exit. The network button ensures the user to connect the local client with the remote server for retrieving 3D building models, plan data as well as online collaborators to the client side. The load and scenario buttons allow the user to get 3D models and different plan data from the local file system into the planning context. The exit button helps users quit the system.

$<<$ Insert Figure 6 here $>>$

On the right hand side of the layout, the task selection area presents the performance button on the bottom. It allows the user to press the button for accessing the planning associated tasks in an offline condition, such as navigation for browsing the model, sort for analysing the model, plan for editing simulation items and simulate for visualizing 4D modelling sequences. In an online condition, retrieved collaborators are listed as silhouettes on the top area. A colour scheme indicates their availability for collaboration. Once the user selects them, the planning associated tasks become collaborative tasks like co-navigate, co-sort, co-plan and co-simulate. Both offline and online planning associated tasks are supported in the work visualization area in the middle of the screen. The implemented prototype applies the same UI layout for the collaborative tasks but has variations in the work visualisation area, in which related panel controls are different in the prototypes.

\section{- Panel control}

Each task of navigate/co-navigate, sort/co-sort, plan/co-plan and simulate/co-simulate has a specific group of panel control buttons presented on the bottom of the main 
screen in their corresponded work visualisation area. The same design scheme is applied in all tasks so that construction planners could always perform their work no matter individually or collaboratively. Figure 7 shows the design scheme for the sort/co-sort task. Its panel control provides a group of left and right arrow buttons to control 3D model's entity topology displaying in an order of either bottom-up or topdown. In the meantime, a set of filter buttons accompanies with these arrow buttons to help the user to analyse the 3D model entities. It can result in specific planning contexts for planners to work in according to their domains. Variations of panel $\underline{\text { control design in each task are dependant on specific user operations, which are }}$ $\underline{\text { identified by task analysis. }}$

$<<$ Insert Figure 7 here $>>$

\section{Usability testing}

The usability testing of the 4D CSCW and UI designs was performed on the basis of a fully implemented working prototype named 4DX. It was in a truly geographically distributed online condition with control factors. The aim of this online testing was to gain insights into planners' collaborative performance so that to discover whether or not the designed collaborative work and related UI were usable and useful to assist collaborators' behaviours. Participants who returned their questionnaire in the user

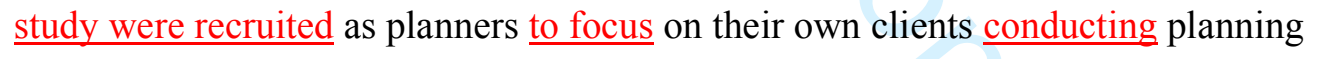
work collaboratively across the Internet. A multiparty video conferencing system named ooVoo was leveraged to bridge the gap among geographically dispersed planners. It provided them with convenience of online human-human interaction in real time during their collaboration.

\section{System configuration}

The usability testing applied a networked multimedia PC with dual-monitor connection in each client. A high-speed broadband network was adopted to underpin its network communication. The dual-monitor setting enabled planners to operate both 4DX and ooVoo in the client. Additionally, the multimedia capability and 
Internet availability in the PC were necessary for remote videoconferencing. Related webcam and headset were configured in the system to support audio/video input/output. A standard mouse and a keyboard were input devices for participants' operations.

Based on the hardware configurations, each client was installed ooVoo and the 4DX client applications. Participants could operate them simultaneously supported by the dual monitors. Because ooVoo allowed up to six people online to communicate at the same time, a small group of planners thus could apply it for the collaborative planning. Particularly, the 4DX server application ran in a PC to provide services for all clients. Figure 8 illustrates the system configurations in the server side.

$<<$ Insert Figure 8 here $>>$

A 3D building model (Figure 6) was selected for the usability testing. This 3D model had sufficient $3 \mathrm{D}$ elements as building information for testing purposes. It contained envelopes, partition walls, slabs, doors, windows (frames and glasses), stairs, handrails, etc. According to the number of participants in the test as well as types of $3 \mathrm{D}$ element in the 3D model, related roles were defined in the server side beforehand. The number of role for the testing consisted with the ooVoo to allow at most six planners in one test session.

\section{Testing setup and task}

There are various usability evaluation methods in the usability engineering. The 4DX usability test adopted the coaching method to reveal usability problems since it enables testers as expert users to take part in the test and hence observe participants in the process to discover their information needs for redesign (pp199-200, Nielsen, 1993). Because speed and time issues in users' collaborative work were less critical, the coaching method is very suitable for testers to evaluate the system's usability in | terms of effectiveness and satisfaction but not efficiency.

Five participants were recruited for the test. They took part in the user study questionnaire survey at the first stage but without experiencing the prototype. In order 
to streamline the test process at the second stage, these participants got acquaintance with the prototype in advance. They were trained in an offline condition to complete individual plan editing work like define, modify and erase plan items. The participants and testers were scattered in two buildings at the campus of the University of Wolverhampton, which provided unlimited wireless Internet access for all users.

According to the coaching method, testers as expert users joined in the test so that to easily identify, record and get through usability problems to task completion in the test. One of the testers in a building played an administration and coach role in the server side during the testing. As the coach tester, he facilitated collaborative work and answered any system-related questions through videoconferencing. Another tester in the client side (named the client tester), together with participants in another building, observed the test process to record usability problems once identified in the test. For the convenience of tester's assistance and observation, all participants were in the same office. In order to avoid direct human-human interaction in the test, they were placed in isolated cubicle desks to focus on their own online collaboration and interaction (Figure 9).

$<<$ Insert Figure 9 here $>>$

The participants were required to create a construction plan collaboratively as task in the test applying the 4DX prototype. This task consisted with the analysed task model (Figure 3, 4,5) to provide observable behaviours of participants' performances for measurement in the test. Participants were expected to perform the designed collaboration of co-plan and co-simulate to overcome collaborative constraints from other collaborators, who need to provide required information and assistance upon requests. Co-navigate and co-talk using ooVoo could function as utilities to provide convenience for collaborators throughout testing procedures. To better control the test, the coach tester would motivate participants to perform co-sort first so that to guide participants to obtain their working contexts in the test. Another control factor was that participants had been trained to master their individual model-based task specifications beforehand.

\section{Testing process and measurement}


Five participants were grouped into two teams to perform the test. In each group test, participants had two sessions to complete their work within 45 minutes. In session one, the client tester took 20 minutes to train participants to master fundamental editing skills using 4DX in an offline condition. In session two, all participants and testers accessed the 4DX prototype online to conduct the collaborative planning task that cost 25 minutes to complete. The measurement focus of the test was placed on questions from participants and observation of their task performances as well as facial expressions. These evaluable focuses in the coaching and the observation methods were also reported by related studies (Dey, 2010; Schmidt et al., 2012; Oliveira et al., 2013).

In a test group, two participants and two testers acted as four different planners for structural, window, door and glass projects respectively to create an integrated project plan through their collaboration. The coach tester initiated the co-sort work first so that to filter out working contexts for all collaborators. Participants in this testing identified building components following the bottom-up topological order when the 3D model was displayed. Frequently asked questions from participants in this process were about building components' identification and ownership. In many cases, this communication was occurred between two participants themselves because these questions were irrelevant to the system and the coach hoped to less intervene their collaboration so that to discover real usability problems.

The building information identification was wholly dependent on participants' cognition about visualised building components because the 3D model in the test was a CAD model without semantic building information like BIM model. Participants showed sufficient knowledge and ability to identify their own building components using input device to interact with the 3D model. Nevertheless, an often asked question was about the usage of designed filter buttons that enable 3D model to be shown in different mode so that to obtain working contexts in the client. During cosort performance, participants maintained a consistent focus using ooVoo and conavigate on the 3D building model for communication. Therefore, they overcame misunderstandings in picking up wrong building components. This co-sort resulted in 
specific planning contexts of structure, window, door and glass for collaborators to work in afterwards.

During the co-plan testing, questions arisen from participants were mainly about whose turn to define simulation items and how to access editing functions. In these cases, testers provided participants with reminders to keep their collaboration continuing. The testers also observed that participants sometimes showed confusion and stopped their work when they turn to perform their own planning work after conducting co-simulate. The co-simulate was correctly performed back and forth by participants in the course of co-plan so that to visually check defined simulation items in terms of logical and temporal corrections. In the co-simulate task performance, a noticeable thing was about asynchronous simulation displaying among participants as they accessed their own project calendars to cause communication confusions for each other. Similar questions and observed phenomena were also shown in another test group. After finishing their tests, a questionnaire survey was conducted for all participants. It was designed to gain feedback regarding the prototype usability according to their experiences in the test (Appendix A).

The final created construction plan in the test was in a hierarchal structure, and imported into the MS Project to gain the same structured plan with a static bar chart. Its relevant 4D simulation sequence was also generated (Zhou et al., 2012). These total test results indicated that the proposed CSCW and UI designs are usable to support planners to conduct collaborative 4D modelling based on a unique 3D model. Enhanced by a multiparty videoconferencing system, geographically dispersed planners are able to gain a robust construction plan combined with 4D simulation through their collaborative work across the Internet. This desired result is subject to the understanding of topological 3D model displaying control to filter out relevant planning contexts for online planners, and their proficiency levels in performing model-based 4D planning in offline conditions. These two aspects were controlled factors in the test to support smooth testing processes.

\section{Participant feedback}


All participants filled in the questionnaire after the test to evaluate the designed CSCW and related UI in terms of satisfaction and effectiveness. It consists of twenty two single selection questions, and each of them has five-point likert scales enumerated to be (1) Strongly Disagree, (2) Disagree, (3) Neutral, (4) Agree and (5) Strongly Agree. The participants' answers are presented by histograms (Figure 10 and 11), which provide a descriptive statistical analysis about user experiences in the test. In general, all participants held a positive point of view on this collaborative 4D planning system.

Regarding UI designs for online individual planning (Figure 10), the answers in Question 1, 3, and 9 indicate that the participants were comfortable with 3D operations applying the standard mouse. The designed 3D navigation tools in the UI of navigate and co-navigate was satisfactory for them to use. The feedback in Question 4 and 11 shows successfulness of the designed visualisation scheme for filtering working context and 4D simulation in the UIs of sort and co-sort as well as simulate and co-simulate. Similarly, the responses in Question 5 and 6 confirm the effectiveness of simulation item definition via the UI of plan and co-plan. It is noted that $40 \%$ participants reflected negative points in Question 2 and 14, which are about analysing 3D model and interactively picking 3D elements from it for sorting and | planning. This result could answer participants' questions about filtering buttons and confused facial expression observed in the test. It is because the participants were still novice users in the test although they got familiar with the editing task beforehand. They need enough training time to reach an expert level to master the system (Nielsen, 1993).

The same reason can explain Question 10 that 20\% participants disagreed with the planning approach. It was considered inconsistent with their prior bar-chart based planning knowledge, which has no need of 3D model analysis and interaction. Such conflicts approved that not all users can reach a skilful level when applying the new 4D planning system. These ergonomic influences imply that there is a learning curve for construction planners to get acquainted with the model-based planning when they access the collaborative 4D modelling system for construction planning and simulation. 
$<<$ Insert Figure 10 here $>>$

The 4D CSCW design in the evaluation got positive feedback. Figure 11 implies that the majority of participants agreed that the 4D CSCW design were helpful, useful and satisfactory for collaborative planning via co-navigate, co-sort, co-plan, co-simulate, and co-talk. Question 7 shows that $80 \%$ of participants agreed that the $4 \mathrm{D}$ system was well designed for them to know their collaborators' performances. There are still $20 \%$ of participants who denied this awareness design. In order to enhance this aspect in the CSCW design, the system can further add cursors movement from all collaborators, or take some other ways to ensure WISIWYS features for all users in collaboration.

\section{$<<$ Insert Figure 11 here $>>$}

\section{Findings}

The CSCW design for the 4D system demonstrated its effectiveness in the test, but it still can be improved for easier transition among different collaborative sessions. The CSCW performances in the collaborative 4D planning were designed to be open and closed sessions. The closed sessions were independent with each other. When initiating one closed session, it needed to terminate another possible live session, and then started a new one. Because of the frequent switch between co-plan and cosimulate for detecting potential conflicts during collaborative planning, it was inconvenient and tedious to repeat this operation. It also made participants confused to return to their own planning work after they performed co-simulate work. An improvement of this pitfall could be the integration of all closed sessions into an explicit collaborative session. The system thus is anticipated interpreting the planners' collaborative activities into implicit collaboration without identifying specific collaborative tasks. This improvement could enhance the coherence and efficiency of collaborative planning to be more natural.

The created panel controls in the UI designs were proven to be effective in the test. Nevertheless, the designed filtering functions for co-sort and co-plan panel control and the project calendar in co-simulate need to be enhanced by creating global effects 
for synchronising project progress management and also keep their local effects for individual convenience, The local freedom in accessing filtering and project calendar in the client, though flexible for individual planning, caused inconsistent planning context when performing co-sort and co-simulate in the test. In order to control group members planning progress in a synchronous state and maintain a consistent planning context for them, local filtering and project calendar functions used by collaborators ought to be under control by a team leader in co-sort and co-plan sessions.

The transparency feature for collaborators needs to be enhanced by displaying collaborators' cursors in the planning context. This design consideration has been reported in related design research (Nam and Wright, 2001). Applying the same design, the planners are expected to figure out collaborators' intentions in the light of their cursors' behaviours in collaboration. Beside this approach, creating an observation feature would enable every collaborator to watch other partners' operations at any time in their local clients. This feature could be very useful particularly when planners have not received their collaborators' data, but wish to know their collaborators' progresses in planning. For a real time collaborative system, this kind of observation feature could positively reinforce the feature of WISIWYS in the CSCW.

The test also showed that a team leader is critical for the real time collaborative 4D modelling in a distributed condition. The coach tester played a team leader role in the test to motivate and coordinate the whole planning process. Considering real time and close-ended features in collaboration, the designed collaborative sessions in CSCW can essentially formulate focus groups for effective co-sort, co-plan, and co-simulate. Such kind of focus group requires a team leader to control collaborative progresses and motivate group members particularly when they are at different skill levels in system operations and locations. In the test, the coach tester acted as the team leader to achieve this effectiveness. In real project situations, master planners in projects could play a team leader role in controlling and coordinating other planners' work.

The coaching method applied in the 4DX usability testing illustrated feasible extensibility for evaluating distributed collaborative systems. The method is originally considered not suitable for remote testing in usability engineering. Taking the 
advantage of PC-based freeware of multiparty videoconferencing system and availability of client testers, it is practical to realise the remote testing shown in 4DX evaluation at low cost. However, this extensibility for more rigorous testing setups is subject to investments for creating networked multiple usability laboratories equipped with behavioural recording, analysis and video surveillance systems. At this networked laboratory circumstance, more complex user behaviours and mental processes could be captured and interpreted by using the method.

\section{$\underline{\text { Discussion }}$}

The use of UCD theories and techniques for CSCW design needs extensive analyses beforehand. As UCD theory framework only provides practical techniques in design approach, workflow, prototype and evaluation for designers to choose, design analysis applying CSCW theories is vitally important to clarify the meaning of the collaborative system, its possible usage, users and their interactive relationship for the purpose of applying UCD techniques subsequently. In terms of 4D CSCW design, related design analysis was clarified from collaborative 4D modelling method, design dimension, design proposition and functional requirement analysis.

The two-stage research strategy in adopting UCD for 4D CSCW design is another characteristic. Because collaborative 4D modelling is a technology-push instead of market-pull application, its investigation had to verify feasibility for individuals and standalone systems, which could not refer to other similar systems by the time of $\underline{\text { research started. As iterative and parallel designs in UCD are different design }}$ approaches, they reject each other in product design to some extend. The combination of them in product development has no existing rules to follow in UCD. Thus, this two-stage strategy applying both iterative and parallel designs in 4D CSCW investigation illustrates a referable example for other product development in the $\underline{\text { similar situation. }}$

As a proof-of-concept study for illustrating a working prototype developed as 4DX. this UCD research for 4D CSCW system follows a human-centred software engineering approach that combines UCD techniques with software engineering processes (Seffah et al., 2009). Referring to prior reports about related technology and 
functionality development (Zhou et al, 2009; 2012), the system research adopts UCD techniques into a waterfall model of software engineering to deliver a socio-technical system. Its disadvantage is obvious that identified design pitfalls cannot be improved easily as the system features had been fully implemented in a working prototype. In case of other similar research or development in future, recommendations are to combine related UCD techniques with the agile model of software engineering so that to keep flexibility in improving the system designs once some functional or nonfunctional improvements are made (Düchting et al., 2007).

$\underline{\text { Research limitations of this user-centred 4D CSCW design are in two aspects. One is }}$ in the clarification of meaning for 4D CSCW. Because the original meaning of 4D modelling is about 4D content development to deliver 3D model-related construction process simulation, the concept of 4D CSCW is evolved from this original vision. Actually, there are more extensive applications from construction project processes that can enrich 4D CSCW contexts in model sharing, mark-up, location-based services, etc. linking with onsite activities. This limitation highlights future research direction in BIM-based CSCW. Another limitation is that the research did not aim to propose related design guidelines or checklists that could be useful for BIM-based $\underline{\mathrm{CSCW} \text { design. As more and more BIM-based collaborative systems are emerging in }}$ $\underline{\text { the future AEC industry, it would be valuable to create practical design guidelines or }}$ checklists to accelerate similar CSCW systems' development using UCD techniques.

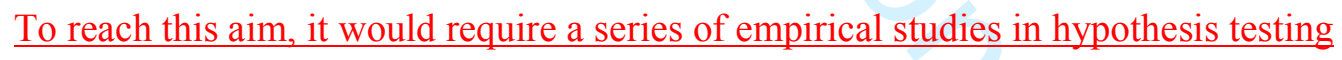
from a social science perspective to investigate BIM-based CSCW design.

\section{Conclusion}

The user-centred 4D CSCW design benefited the prototype to be developed as a usable socio-technical system. The revealed design pitfalls in awareness, transparency and transition among collaborative sessions are expected to overcome in the future. By enhancing these weaknesses in CSCW and related UI designs, model-based collaborative 4D modelling software can positively underpin geographically dispersed planners to collaboratively gain a robust construction plan through simulation. Extensive training is compulsory for construction planners to master the model-based 
planning before applying similar software for real project practices. Further real project tests are expected to carry out on the basis of this controlled test and enhancement to examine its applicability.

Applying CSCW and UCD theories to design collaborative 4D modelling is effective and yet popular in the current AEC industry. Demonstrated by the reported study, general needs from collaborative BIM applications can be clarified and identified following the guidance from $\mathrm{CSCW}$ theories. On the other hand, UCD theories and techniques provide practitioners with flexible options for designing and evaluating proposed socio-technique prototypes. Creative selections of right usability testing methods, e.g. distributed coaching method, and design approaches, e.g. the parallel and iterative design combination, are the key for design success.

The model-based collaboration in BIM for teamwork are received more attention in the modern AEC industry. Adopting CSCW and UCD theories reported in this paper can be helpful to deliver usable socio-technical solutions to facilitate teamwork in other dimensional modelling like cost analysis, energy analysis for sustainable design, facility management, etc. Through this approach, complex collaborative BIM applications can therefore be developed into usable systems for wider acceptance by the AEC industry.

\section{Reference}

Baiden, B. K., Price, A.D.F. and Dainty, A. R. J. (2006), "The extent of team integration within construction projects", International Journal of Project Management, Volume 24, Issue 1, January 2006, pp. 13-23.

Baxter G. and Sommerville, I. (2011), "Socio-technical systems: From design methods to systems engineering", Interacting with Computers (2011) 23 (1): 4-17

Chau, K. W., Anson, M. and Zhang, J. P. (2005), “4D dynamic construction management and visualization software: 1. Development", Automation in Construction, Volume 14, Issue 4, August 2005, pp. 512-524. 
Collier, E. and Fischer, M. (1996), "Visual-based scheduling: 4D modelling on the San Mateo County Health Centre", Proceedings of the 3rd ASCE Congress on Computing in Civil Engineering 1996, Anaheim, CA.

Dix, A., Finlay, J., Abowd G., and Beale, R. (2003), "Human-Computer Interaction", $\underline{3 \text { rd Edition. Prentice Hall }}$

Dey, A.K. and Mann, D.D. (2010), “A complete task analysis to measure the workload associated with operating an agricultural sprayer equipped with a navigation device”, Applied Ergonomics 41 (2010) 146-149

Düchting, M., Zimmermann, D. and Nebe, K. (2007), "Incorporating User Centred Requirement Engineering into Agile Software Development", Human-Computer Interaction. Interaction Design and Usability, Lecture Notes in Computer Science Volume 4550, 2007, pp 58-67

Eastman, C., Teicholz, P., Sacks, R. and Liston, K. (2011), “BIM Handbook: A Guide to Building Information Modeling for Owners, Managers, Designers, Engineers and Contractors", John Wiley \& Sons 2011, ISBN 0470541377

Fischer, G., Giaccardi, E., Eden, H., Sugimoto, M. and Ye, Y. (2005), "Beyond binary choices: Integrating individual and social creativity", International Journal of HumanComputer Studies, Volume 63, Issues 4-5, October 2005, pp. 482-512.

Grilo, A. and Jardim-Goncalves, R. (2010), "Value proposition on interoperability of BIM and collaborative working environments", Automation in Construction, Volume 19, Issue 5, August 2010, pp. 522-530.

Heesom, D. and Mahdjoubi, L. (2004), “Trends of 4D CAD applications for construction planning", Construction Management \& Economics, 22, (2004) 171-182.

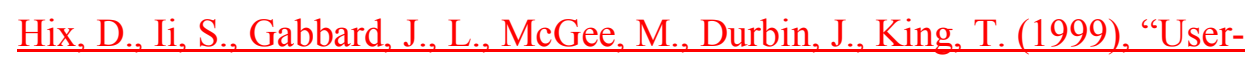
Centered Design and Evaluation of a Real-Time Battlefield Visualization". Virtual Environment. IEEE Virtual Reality Conference (VR'99) 
Isikdag, U. and Underwood, J. (2010), “Two design patterns for facilitating Building Information Model-based synchronous collaboration", Automation in Construction, Volume 19, Issue 5, August 2010, pp. 544-553.

Kang, J. H., Anderson, S. D. and Clayton, M. J. (2007), "Empirical Study on the Merit of Web-Based 4D Visualization in Collaborative Construction Planning and Scheduling”, Journal of Construction Engineering and Management. Volume 133, Issue 6, (2007) pp. 447-461.

Koo, B. and Fischer, M. (2000), "Feasibility Study of 4D CAD in Commercial Construction", Journal of Construction Engineering and Management, Volume 126, Issue 4 (July 2000).

Mayhew, D., J. (1999): “The Usability Engineering Lifecycle”, Academic Press, San $\underline{\text { Diego }(\mathrm{CA})}$

Mills, K. L. (2003) “Computer-Supported Cooperative Work”, Encyclopaedia of Library and Information Science, Second Edition, pp. 666-677.

Nam T. J. and Wright, D. (2001), “The development and evaluation of Syco3D: a real-time collaborative 3D CAD system”, Design Studies, Volume 22, Issue 6, November 2001, pp. 557-582.

Nielsen, J. (1993), “Usability Engineering”, SunSoft, California, Morgam Kaufmann 1993.

Nielsen, J., and Faber, J., M. (1996), "Improving System Usability Through Parallel Design". IEEE Computer Vol. 29, No. 2 (1996) 29-35

Norman, D. (1988), "The Psychology of Everyday Things". Basic Books 
Oliveira, A., Pinho, C., Monteiro, S., Marcos, A., Marques, A. (2013), "Usability testing of a respiratory interface using computer screen and facial expressions videos", Computers in Biology and Medicine 43 (2013) 2205-2213

Paternò, F. (2000), "Model-Based Design and Evaluation of Interactive Applications", Springer-Verlag London Limited 2000.

Prescott, J. (1998), “Rethinking of Construction”, Department of Trade and Industry, URN 03/951 Available at:

http://www.architecture.com/files/RIBAHoldings/PolicyAndInternationalRelations/Po

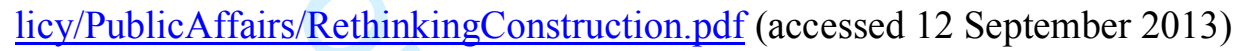

\section{Pruitt, J. and Adlin, T. (2006). "The Persona Lifecycle", Morgan Kaufmann Publishers, Publish date: April 2006, ISBN-13: 9780125662512}

Rezgui, Y. and Zarli, A. (2006), "Paving the way to the vision of digital construction: a strategic roadmap”, Journal of Construction Engineering and Management, 132 (7) 2006, pp. 767-776.

Schmidt, M., Laffey, J.M., Schmidt, C.T., Wang, X. and Stichter, J. (2012), "Developing methods for understanding social behavior in a 3D virtual learning environment", Computers in Human Behavior 28 (2012) 405-413

Schmuller, J. (2004), "Sams Teach Yourself UML in 24 Hours: Complete Starter Kit”, Published by Sams Publishing, 2004, ISBN 067232640X, 9780672326400.

\section{Seffah, A., Vanderdonckt, J., Desmarais, M. C. (2009), "human-centred software engineering", Human-Computer Interaxtion Series 8, Springer.}

Sher, W., Sheratt, S., Williams, A., Gameson, R. (2009), "Heading into new virtual environments: what skills do design team members need?", ITcon Vol. 14, (2009), Special Issue Technology Strategies for Collaborative Working, pg. 17-29, http://www.itcon.org/2009/4 (accessed 12 September 2013) 
Shen, W., Hao, Q., Mak, H., Neelamkavil, J., Xie, H., Dickinson, J., Thomas, R., Pardasani, A. and Xue, H. (2010), "Systems integration and collaboration in architecture, engineering, construction, and facilities management: A review", Advanced Engineering Informatics, Volume 24, Issue 2, April 2010, pp. 196-207.

Silva, A. M. D. and Baranauskas, M.C.C. (2000), “The Andon System: Designing a CSCW Environment in a Lean Organization", Proceedings of the 6th International Workshop on Groupware (CRIWG'00), 2000, pp.130.

Singh, V., Gu, N., and Wang, X. (2011), "A theoretical framework of a BIM-based multi-disciplinary collaboration platform", Automation in Construction, Volume 20, Issue 2, March 2011, Pages 134-144

Synchro (2010), “Synchro user guide”, version 3.1415.1. Synchro Ltd. April 2010.

Wang, Y., Yang, J. and Shen, Q. (2007), “The application of electronic commerce and information integration in the construction industry", International Journal of Project Management, Volume 25, Issue 2, February 2007, pp. 158-163.

Zhou, W., Heesom, D., Georgakis, P., Nwagboso, C. and Feng, A. (2009), “An interactive approach to collaborative 4D construction planning”, ITcon Vol. 14, 2009 , Special Issue Technology Strategies for Collaborative Working, pg. 30-47, http://www.itcon.org/2009/5 (accessed 12 September 2013)

Zhou, W., Georgakis, P., Heesom, D. and Feng, X. (2012), "Model-based Groupware Solution for Distributed Real-time Collaborative 4D Planning through Teamwork", Journal of Computing in Civil Engineering, Vol. 26, No. 5, September 1, 2012, pp. 597-611.

\section{Appendix A Questionnaire of CSCW and UI Designs for 4D Modelling}

01) I quickly got familiar with navigation in the $3 \mathrm{D}$ environment using the input device.

$\square$ Strongly Disagree $\square$ Disagree $\square$ Neutral $\square$ Agree $\square$ Strongly Agree 
02) It was quite easy for me to pick desired $3 \mathrm{D}$ elements for sorting and planning. $\square$ Strongly Agree $\square$ Agree $\square$ Neutral $\square$ Disagree $\square$ Strongly Disagree

03) I could easily adapt my manipulation in $3 \mathrm{D}$ navigation using the input device.

$\square$ Strongly Disagree $\square$ Disagree $\square$ Neutral $\square$ Agree $\square$ Strongly Agree

04) The process of defining project tasks was easy and the visualisation ensured assisted me in checking defined project tasks.

$\square$ Strongly Disagree $\square$ Disagree $\square$ Neutral $\square$ Agree $\square$ Strongly Agree

05) I was quite familiar with the plan task definition which keeps consistency with my acquired knowledge on project planning.

$\square$ Strongly Agree $\square$ Agree $\square$ Neutral $\square$ Disagree $\square$ Strongly Disagree

06) The defined hierarchal task items kept consistent with what I expected to see.

$\square$ Strongly Disagree $\square$ Disagree $\square$ Neutral $\square$ Agree $\square$ Strongly Agree

07) It was convenient for me to review my collaborator's state during collaborative planning sessions.

$\square$ Strongly Disagree $\square$ Disagree $\square$ Neutral $\square$ Agree $\square$ Strongly Agree

08) The collaborative sessions provided assistance during my planning operations. $\square$ Strongly Disagree $\square$ Disagree $\square$ Neutral $\square$ Agree $\square$ Strongly Agree

09) I was clear on how to control my navigation in terms of the 3D model's zoom, pan and rotate.

$\square$ Strongly Disagree $\square$ Disagree $\square$ Neutral $\square$ Agree $\square$ Strongly Agree

10) I was satisfied with the approach of plan item definition as it is almost the same with my prior knowledge of project planning.

$\square$ Strongly Disagree $\square$ Disagree $\square$ Neutral $\square$ Agree $\square$ Strongly Agree 
11) The visualisation and simulation provided me with sufficient indications to identify the defined project tasks.

$\square$ Strongly Disagree $\square$ Disagree $\square$ Neutral $\square$ Agree $\square$ Strongly Agree

12) The plan item definition realised what I expected to see in planning work.

$\square$ Strongly Disagree $\square$ Disagree $\square$ Neutral $\square$ Agree $\square$ Strongly Agree

13) I was aware of my collaborator's planning progress in the planning session.

$\square$ Strongly Disagree $\square$ Disagree $\square$ Neutral $\square$ Agree $\square$ Strongly Agree

14) I could conveniently choose my desired $3 \mathrm{D}$ elements in sorting and planning.

$\square$ Strongly Disagree $\square$ Disagree $\square$ Neutral $\square$ Agree $\square$ Strongly Agree

15) In general, I was satisfied with this collaborative approach to my planning work.

$\square$ Strongly Disagree $\square$ Disagree $\square$ Neutral $\square$ Agree $\square$ Strongly Agree

16) I was satisfactory to exam the $3 \mathrm{D}$ building model and its components in the conavigate session.

$\square$ Strongly Disagree $\square$ Disagree $\square$ Neutral $\square$ Agree $\square$ Strongly Agree

17) I could get assistance from other collaborators in the co-navigate session for cosorting and co-planning.

$\square$ Strongly Disagree $\square$ Disagree $\square$ Neutral $\square$ Agree $\square$ Strongly Agree

18) I was satisfied with co-sort collaboration as it provided a clear collaborative context to identify $3 \mathrm{D}$ elements for planning.

$\square$ Strongly Disagree $\square$ Disagree $\square$ Neutral $\square$ Agree $\square$ Strongly Agree

19) I was aware of my collaborators' 3D elements and hence sorted my own 3D elements correctly in the co-sort session.

$\square$ Strongly Disagree $\square$ Disagree $\square$ Neutral $\square$ Agree $\square$ Strongly Agree

20) The co-plan session enabled me to define my own schedule while to consider other collaborators' planning work in integration. 
$\square$ Strongly Disagree $\square$ Disagree $\square$ Neutral $\square$ Agree $\square$ Strongly Agree

21) I was satisfied with the co-simulate across the network since it enabled me to check my own schedule as well as other collaborators' planning work simultaneously. $\square$ Strongly Disagree $\square$ Disagree $\square$ Neutral $\square$ Agree $\square$ Strongly Agree

22) The co-talk in the planning provided me chances to coordinate planning process and consider appropriate strategies with other collaborators together.

$\square$ Strongly Disagree $\square$ Disagree $\square$ Neutral $\square$ Agree $\square$ Strongly Agree 


\begin{tabular}{|c|c|}
\hline Reviewers Comments to Author & $\begin{array}{l}\text { Authors Response to Reviewers } \\
\text { Comments }\end{array}$ \\
\hline $\begin{array}{l}\text { 1. Please remove bullet points from within the } \\
\text { Abstract. }\end{array}$ & 1. Done in pp.1 \\
\hline $\begin{array}{l}\text { 2. Please incorporate Paper type beneath } \\
\text { Keywords. }\end{array}$ & 2. Done in pp.1 \\
\hline 3. All et al's should be italicised throughout. & 3. Done throughout the whole paper \\
\hline $\begin{array}{l}\text { 4. Please make reference to original source (and not } \\
\text { through corroborated sources) e.g. Egan. }\end{array}$ & 4. Revised in pp. 2 in the end of the first paragraph \\
\hline $\begin{array}{l}\text { 5. There are a lot of abbreviations in this paper, } \\
\text { some of which are used multiple times. If and where } \\
\text { possible please try to rationalise these. E.g. CSCW, } \\
\text { BIM, etc. }\end{array}$ & $\begin{array}{l}\text { 5. The paper always provides abbreviations when } \\
\text { related terms appear initially and need to be reused } \\
\text { more times in later contents. }\end{array}$ \\
\hline $\begin{array}{l}\text { 6. A Research Methodology section is needed prior } \\
\text { to the work being presented. This needs to include } \\
\text { the ontological and epistemological positioning, } \\
\text { together with a detailed justification of the Research } \\
\text { methodological approach adopted, supported by the } \\
\text { method of measurements, units of analysis, metrics } \\
\text { etc. }\end{array}$ & $\begin{array}{l}\text { 6. The research method section is amended as } \\
\text { Theory of user-centred design from pp. } 4 \text {. It } \\
\text { delineates its theory framework, related techniques, } \\
\text { suitability for socio-technical research, etc. In } \\
\text { conjunction with introduction section, this research } \\
\text { method section helps to provide readers with } \\
\text { fundamental understanding of how the design } \\
\text { research work was carried out. }\end{array}$ \\
\hline $\begin{array}{l}\text { 7. A discussion section is needed. This should } \\
\text { discuss the main research findings of this work with } \\
\text { respect to items of particular significance. These } \\
\text { areas should (wherever possible) link back to } \\
\text { seminal authors or similar work in this area so that } \\
\text { comparisons and conclusions can be drawn. The } \\
\text { conclusion section would then naturally refer to } \\
\text { these from a holistic perspective e.g. }\end{array}$ & $\begin{array}{l}\text { 7. The discussion section is amended in pp.22. It } \\
\text { highlights characteristics of UCD and CSCW } \\
\text { combination for the research into 4D CSCW. At the } \\
\text { same time, it points out their limitations in the } \\
\text { reported study. This research method also links to } \\
\text { human-centred software engineering research to } \\
\text { demonstrate a referable research approach to socio- } \\
\text { technical system design/development. }\end{array}$ \\
\hline
\end{tabular}
generalisability, repeatability, research limitations, future research etc.

8. There needs to be a clear delineation between the end of the literature review section and the start of the R.M. section. The work undertaken should then naturally follow after the R.M. section.

9. This paper seems to present work prior to the findings section. It is important to present the work in a logical way.

\section{Please explain WISIWYS.}

11. A conclusion section is needed which identifies the general approach and supportive rationale. This needs to be extended to tease out the precise research findings this paper offers; the link back to

8. This required information is amended in the final part of the introduction section. It can guide readers to know what theories the reported work roots in.

9. The whole paper is re-structured to help readers understand how the research work was performed step-by-step.

10. It has been explained when the term "What-ISee-Is-What-You-See" is appeared initially in pp.9 and reused in pp.20

11. The conclusion part highlights the applicability of UCS and CSCW theories for the design/develop socio-technical systems in general and $\mathrm{nD}$ modeling system in particular for the AEC industry. The 
seminal literature in this respect; the precise nature of the assumptions made; the validity of findings in respect of generalisability, repeatability, etc. general research strategy can follow the reported study to identify design proposition as assumption underpinned by CSCW theories, and then prototype and evaluate for verification based on UCD theories and techniques.

The author appreciates the reviewer's suggestions to help improve the paper quality. The paper has been significantly revised and amended with extensive information. Hence, the title of this paper is also changed into "User-Centred Design for Collaborative 4D Modelling" from the old one. 


\section{List of table}



Table 2 Relationship among proposed 4D CSCW, design areas and working sessions 


\section{List of figure}

Figure 1: PBS+WBS approach to 4D modelling

Figure 2: Use case diagram of collaborative 4D modelling

Figure 3: Task model of online planner

Figure 4: Task model of collaborator

Figure 5: Task model of launch a collaborative session

Figure 6: UI layout

Figure 7: Panel control UI design for Sort/Co-Sort

Figure 8: 4DX sever side system configurations for the usability testing

Figure 9: Testing setup

Figure 10: Results of participants' feedback regarding UI/interaction design

Figure 11: Results of participants' feedback regarding CSCW design 

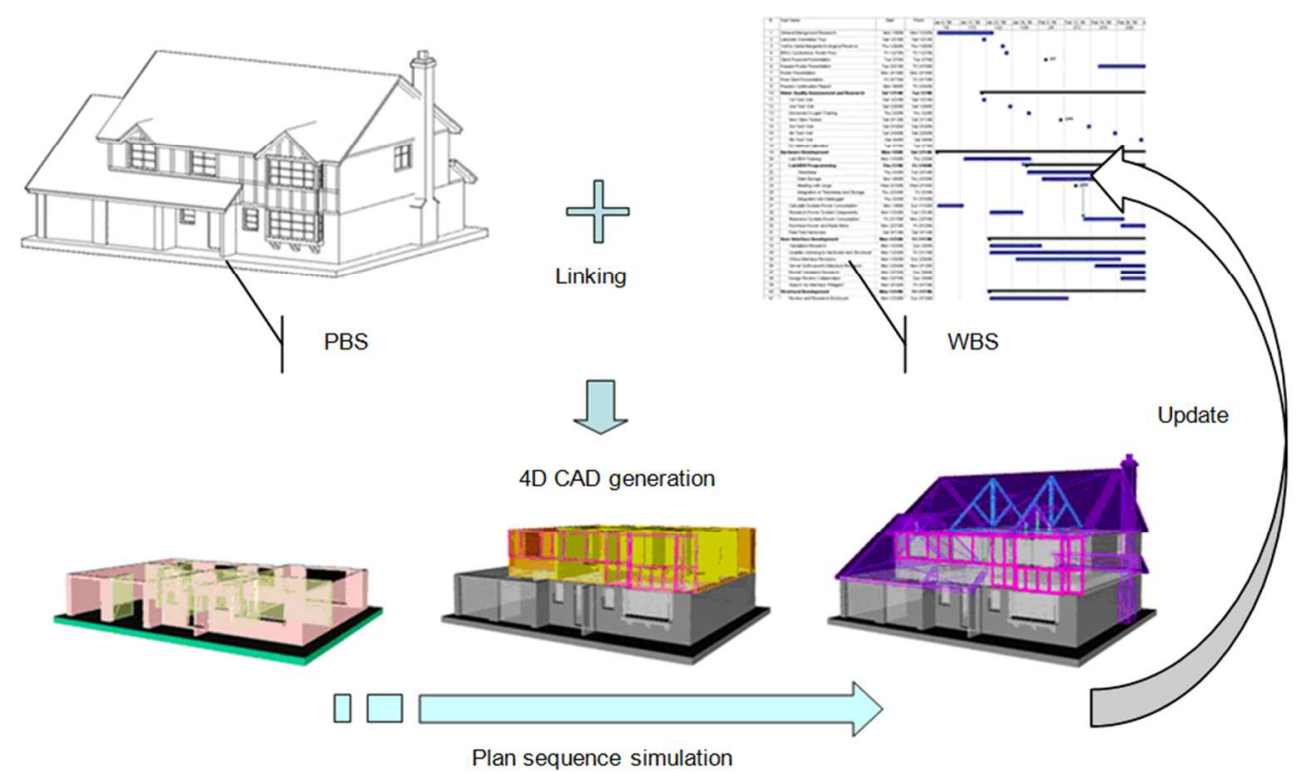

$82 \times 48 \mathrm{~mm}(300 \times 300$ DPI $)$ 


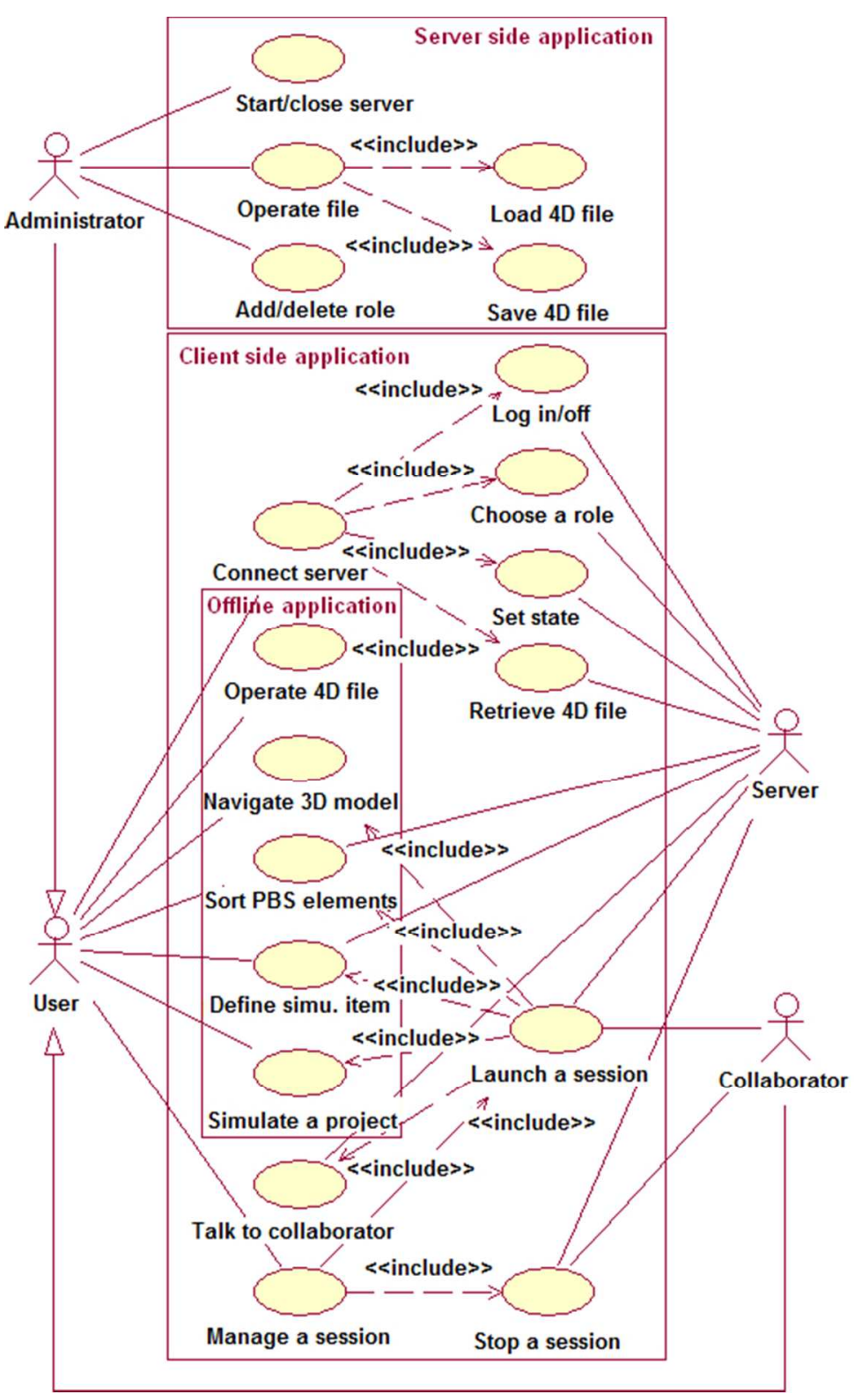

$44 \times 71 \mathrm{~mm}(300 \times 300$ DPI $)$ 


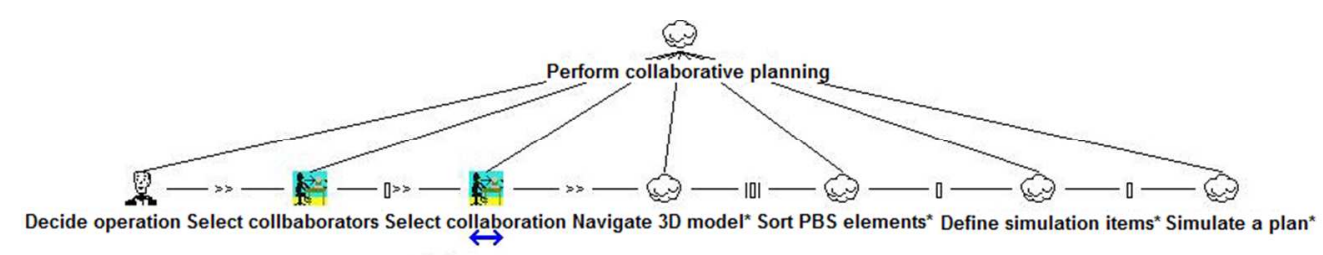

$76 \times 14 \mathrm{~mm}(300 \times 300 \mathrm{DPI})$ 
$64 \times 13 \mathrm{~mm}(300 \times 300 \mathrm{DPI})$ 
$22 \times 10 \mathrm{~mm}(300 \times 300$ DPI $)$ 


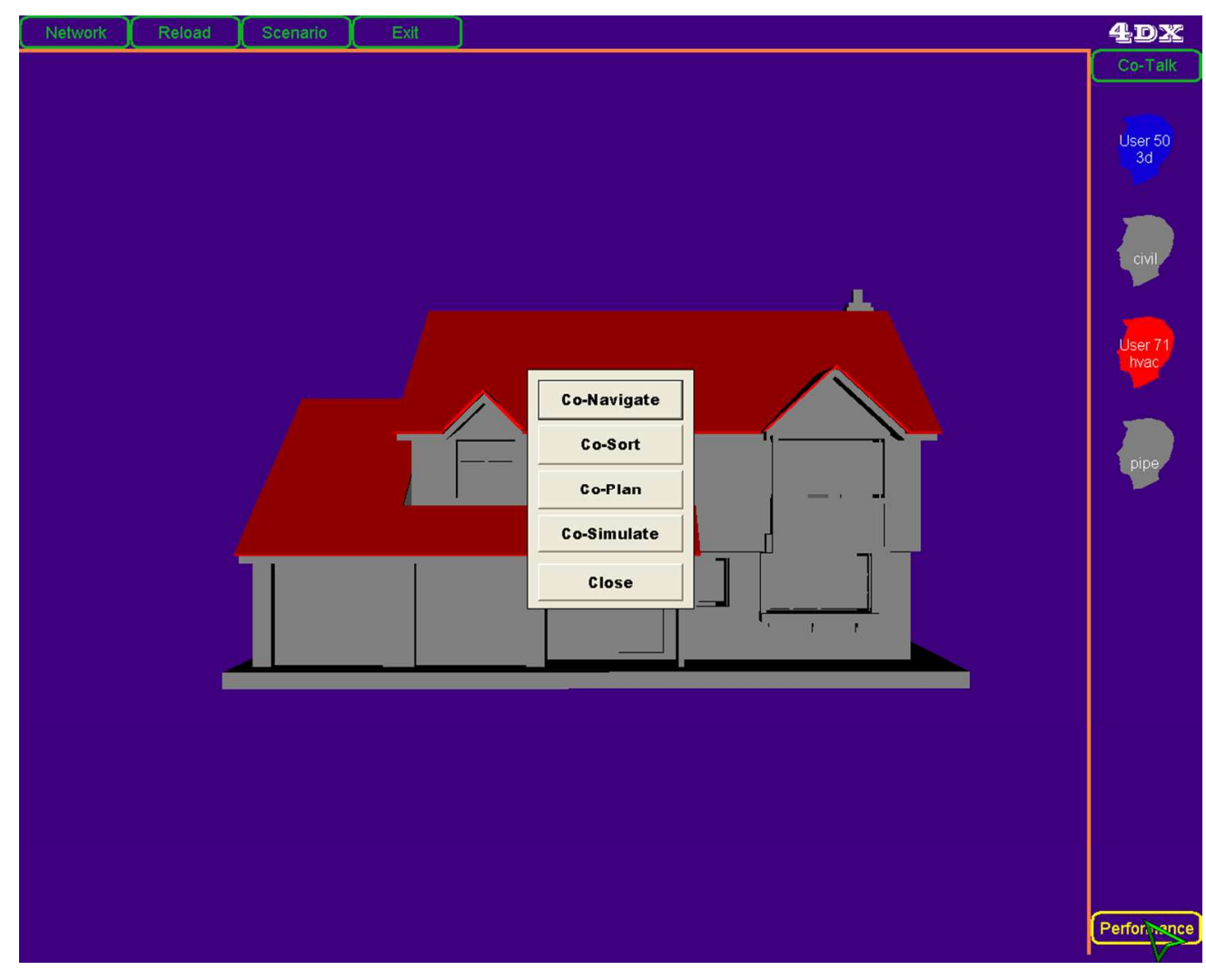

$108 \times 86 \mathrm{~mm}(300 \times 300 \mathrm{DPI})$ 


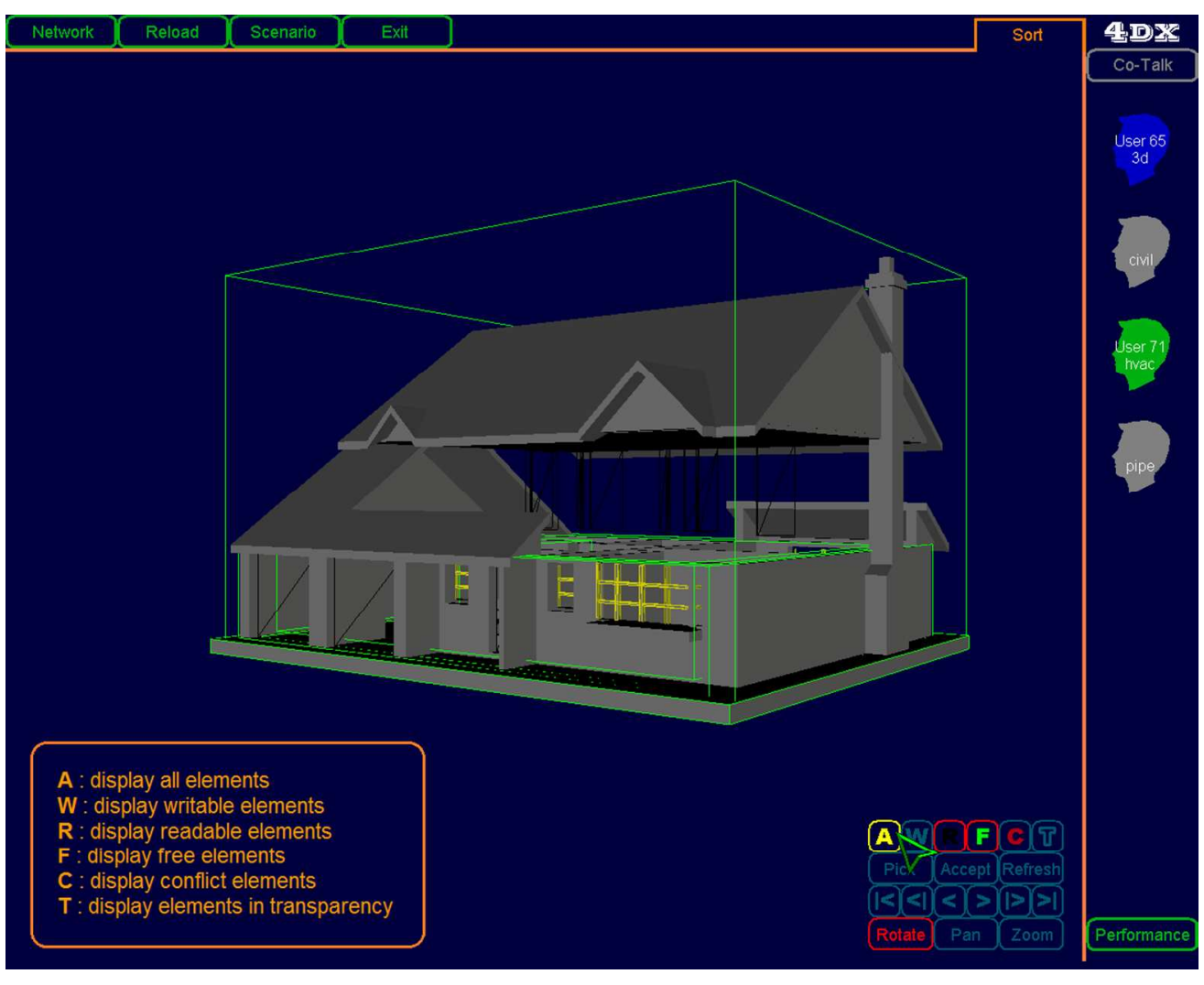

$108 \times 86 \mathrm{~mm}(300 \times 300 \mathrm{DPI})$ 


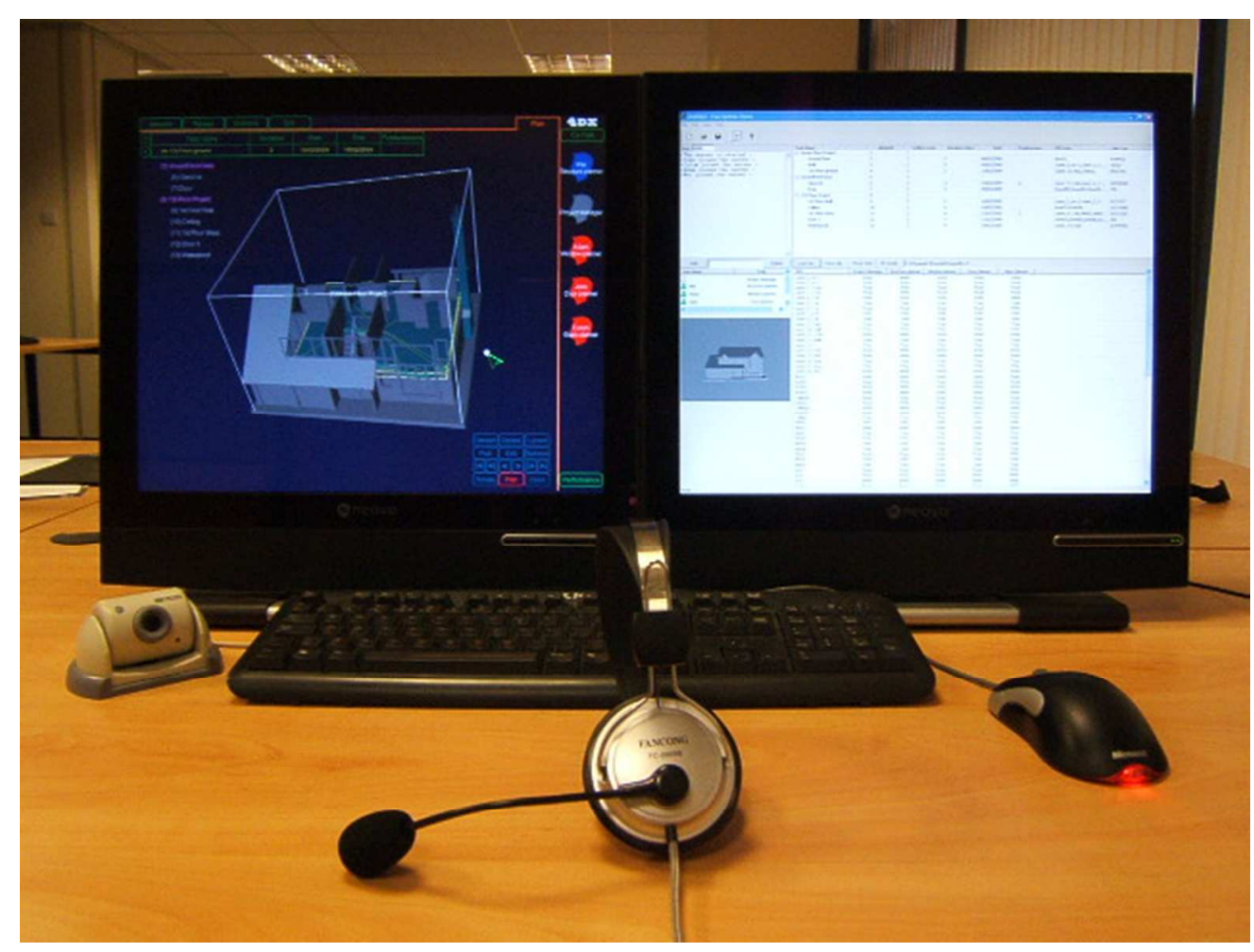

$54 \times 40 \mathrm{~mm}(300 \times 300$ DPI $)$ 
Construction Innovation: Information, Process, Management

Page 44 of 46

$$
\begin{aligned}
& 1 \\
& 1 \\
& 2 \\
& 3 \\
& 4 \\
& 5 \\
& 6 \\
& 7 \\
& 8 \\
& 9 \\
& 10 \\
& 11 \\
& 12 \\
& 13 \\
& 14 \\
& 15 \\
& 16 \\
& 17 \\
& 18 \\
& 19 \\
& 20 \\
& 21 \\
& 22 \\
& 23 \\
& 24 \\
& 25 \\
& 26 \\
& 27 \\
& 28 \\
& 29 \\
& 30 \\
& 31 \\
& 32 \\
& 33 \\
& 34 \\
& 35 \\
& 36 \\
& 37 \\
& 38 \\
& 39 \\
& 40 \\
& 41 \\
& 42 \\
& 43 \\
& 44 \\
& 45 \\
& 46 \\
& 47 \\
& 48 \\
& 60 \\
& 49 \\
& 50 \\
& 51 \\
& 52 \\
& 53 \\
& 54 \\
& 55 \\
& 59
\end{aligned}
$$

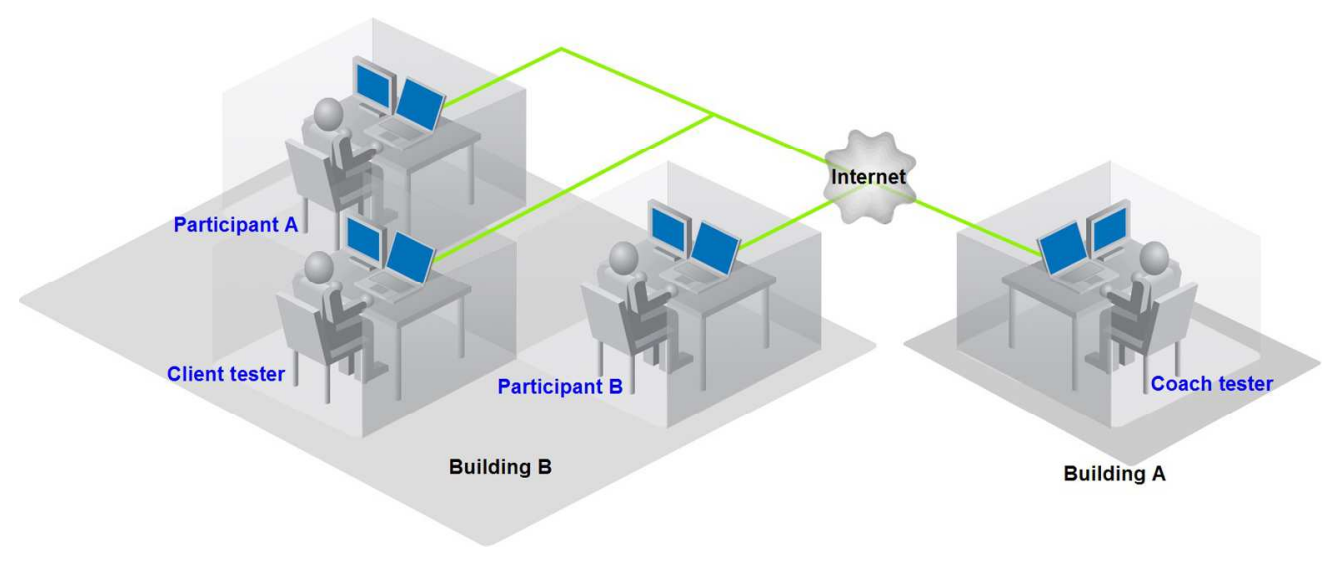

$$
\text { 149x60mm (300 x } 300 \text { DPI) }
$$




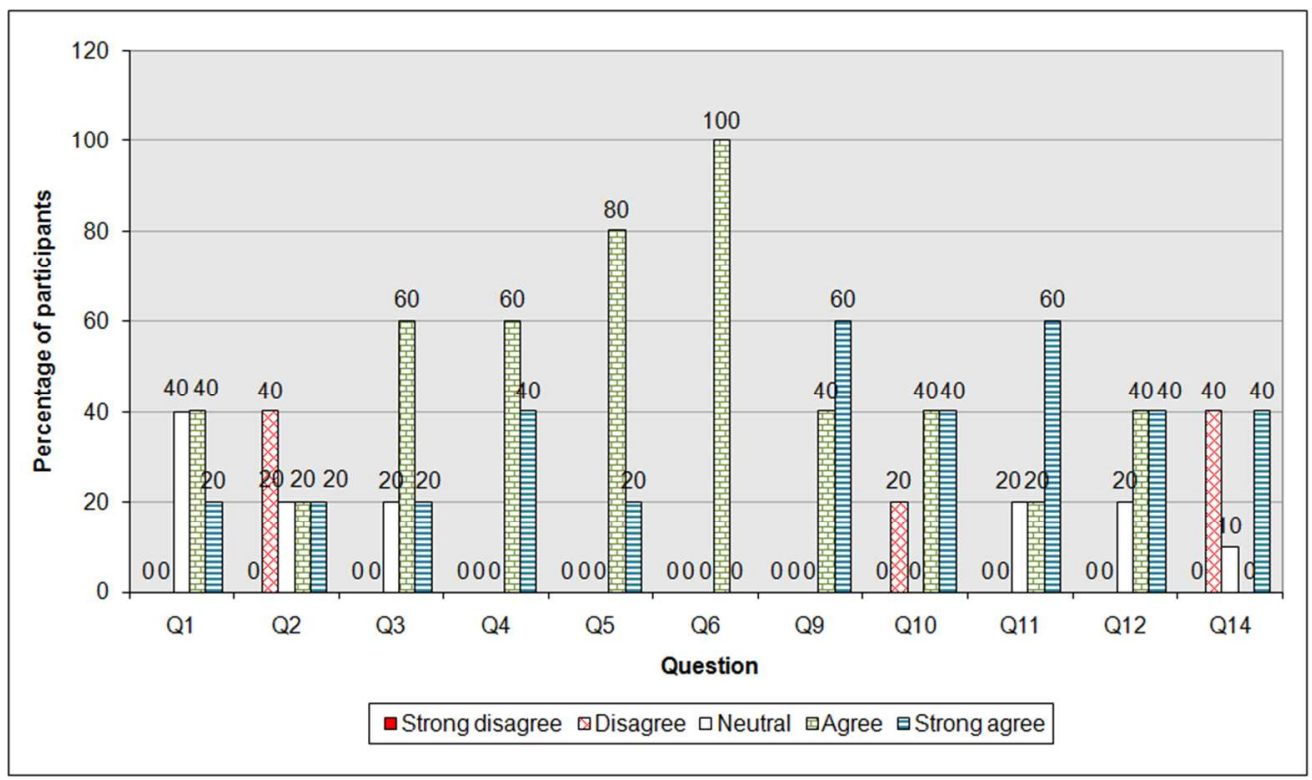

$77 \times 45 \mathrm{~mm}(300 \times 300$ DPI $)$ 


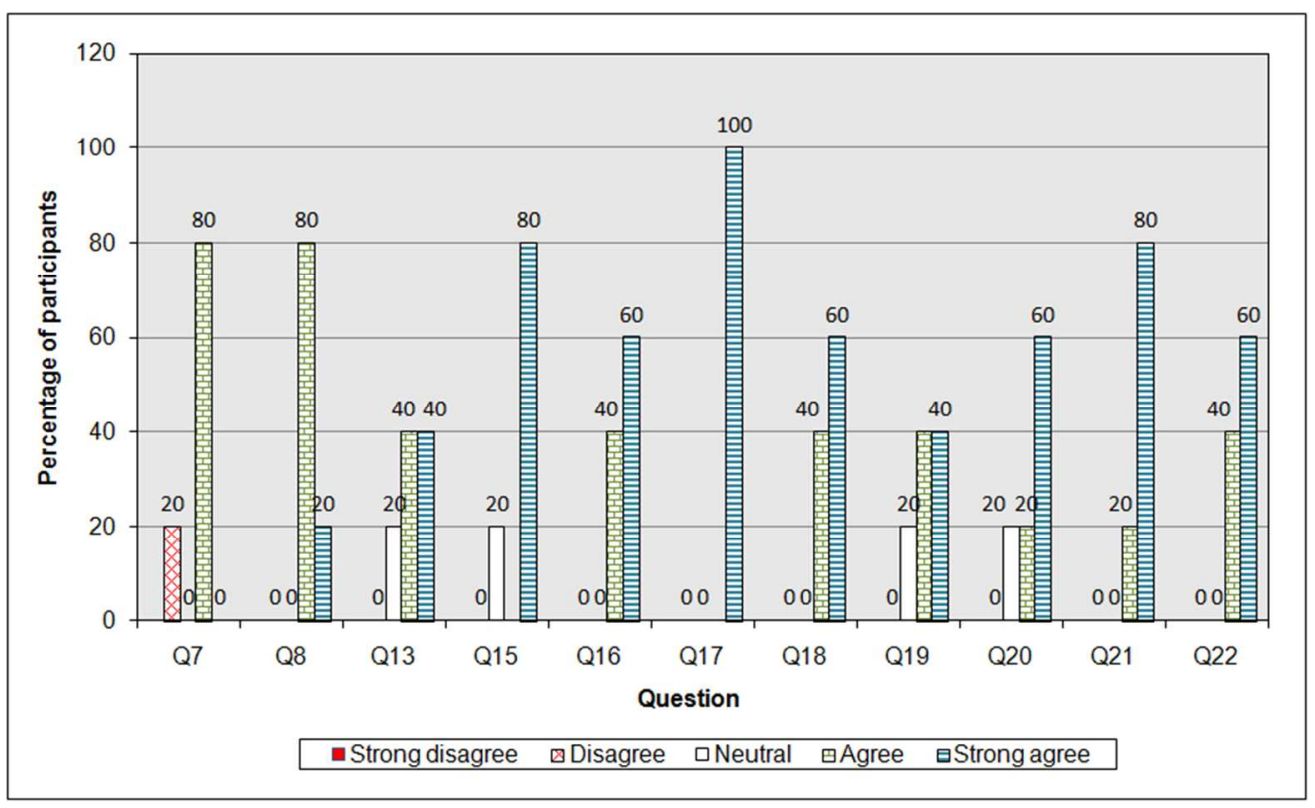

$73 \times 44 \mathrm{~mm}(300 \times 300$ DPI $)$ 